\title{
Morar no meio rural: o cotidiano dos/das jovens rurais de um município baiano
}

\author{
Catarina Malheiros da Silva ${ }^{1}$ \\ ${ }^{1}$ Instituto Federal de Educação, Ciência e Tecnologia de Goiás - IFG. Campus Goiânia Oeste. Avenida C-198, \\ Qd. 500, Jardim América. Goiânia - GO. Brasil. catems14@gmail.com.
}

\begin{abstract}
RESUMO. O entendimento de como a juventude rural tem sido tematizada é bastante pertinente, pois historicamente as instituições educativas escolares partem do princípio de que os(as) jovens brasileiros provêm de espaços onde as práticas de sociabilidade, as relações de gênero, o projeto de vida e tantas outras dimensões são homogêneos e únicos. No que se refere à invisibilidade dos jovens que vivem no meio rural, observa-se o predomínio de um estereótipo pautado em uma visão urbana da noção de juventude, anulando as singularidades da vida destes. Nesse sentido, o presente artigo se propõe a compreender as percepções dos/das jovens sobre o lugar em que vivem, bem como as experiências cotidianas vivenciadas por estes nos espaços de circulação social. Foram realizados 10 grupos de discussão com jovens do sexo masculino e feminino, matriculados nos anos finais do ensino fundamental de uma escola localizada em distrito rural de um município da Bahia. Os resultados da pesquisa desenvolvida apontam que a formulação de políticas públicas educativas deve estar articulada com um projeto de país e de campo que reconheça a existência do meio rural como lugar de vida, trabalho, cultura e lazer.
\end{abstract}

Palavras-chave: Jovens Rurais, Meio Rural, Cotidiano, Educação Básica. 


\title{
Living on the countryside: the quotidian life of the rural youth of a city in Bahia
}

\begin{abstract}
The understanding of how the countryside youth has been theorized is quite relevant, because historically the school educational institutions assume that Brazilian youth come from spaces where sociability practices, gender relations, life projects and many other dimensions are homogeneous and unique. Regarding the invisibility of the countryside youth, one can observe the preponderance of a stereotype based on an urban vision of youth, nullifying their life's singularities. Hence, this article intends to present the perceptions of the youth about the places where they live, as well as the daily experiences lived by them in these social movement spaces. There were ten groups of discussion with male and female students, enrolled in the final years of middle school of an institution located in the countryside district of a city in Bahia. The result of the developed research points that the formulation of educational public policies must be articulated with a country and provincial project that recognizes the existence of the countryside as a place of life, work, culture and leisure.
\end{abstract}

Keywords: Rural Youth, Countryside, Quotidian Life, Basic Education. 


\section{Vivir en el medio rural: la vida cotidiana de los jóvenes rurales de una ciudad de Bahia}

RESUMEN. La comprensión de cómo la juventud rural ha sido abordada es muy relevante, porque históricamente nuestras instituciones educativas asumen de que los jóvenes brasileños se originan de áreas donde las prácticas de sociabilidad, relaciones de género, el proyecto de vida y tantas otras dimensiones son homogéneas y únicas. En cuanto a la invisibilidad de los jóvenes que viven en el medio rural, se constata el predominio de un estereotipo basado en una visión urbana del concepto de juventud, anulando las peculiaridades de la vida. En este sentido, el presente artículo pretende presentar las percepciones de los jóvenes sobre el lugar dónde viven, así como las experiencias cotidianas vividas por ellos en espacios de movimiento social. Se condujeron 10 grupos de discusión con jóvenes de ambos géneros, inscritos en los años finales de la enseñanza básica de una escuela ubicada en un distrito rural de una ciudad de Bahia. Los resultados de las investigaciones desarrolladas demuestran que la formulación de políticas públicas de educación debe ser articulada con un proyecto de país y de campo que reconozca la existencia del medio rural como un lugar de vida, trabajo, cultura y ocio.

Palabras-clave: Jóvenes Rural, Medio Rural, Vida Cotidiana, Educación Básica. 


\section{Introdução}

A referência ao jovem, nos dias atuais, precisa levar em consideração a heterogênea realidade das sociedades contemporâneas. A ambiguidade e a imprecisão do conceito de juventude ou sobre o que é ser jovem são algumas das características dessa situação de complexidade, daí a fragilidade de definições que situam o conceito em fronteiras fixas. Margulis (2001) e Dayrell (2007), ao discutirem a juventude, situamna como produto de uma construção histórica, social e cultural, marcada pela diferença social, pelo sexo, lugar em que vivem, grupo religioso e pela geração à qual pertencem. Os autores rompem ainda com a preponderância da dimensão etária na conceituação de juventude.

No meio rural brasileiro, espaço cada vez mais heterogêneo e diversificado, são tecidas relações socioculturais singulares, ao mesmo tempo em que se mantêm vínculos de dependência com os centros urbanos. Nesse sentido, "as ruralidades se expressam de formas diferentes em universos culturais, sociais e econômicos heterogêneos". (Pereira, 2004, p. 344). O mundo rural pode ser compreendido então, como lugar de vivências peculiares, em consonância com outras formas de organização social. Por outro lado, pensar o meio rural a partir das suas singularidades nos possibilita reportar à "invisibilidade" que atinge a população rural como um todo. Para autores como Veiga (2003) e Abramovay (2004) as condições precárias a que são submetidos os sujeitos do campo fortalecem a calcificação de imagens discriminatórias sobre a população rural. $\mathrm{O}$ desconhecimento e negação dos modos de vida dessa população fazem com que as demandas existentes no campo sejam negligenciadas.

A juventude rural figura como parcela dessa população ainda bastante desconhecida para as instituições educativas, dado o não reconhecimento de problemas específicos que os afetam, ao contrário dos jovens urbanos que são vislumbrados pelas instituições, especialmente no que diz respeito à proposição de políticas públicas. Também não são reconhecidas as práticas de sociabilidade e as vivências culturais, aportadas num contexto específico. Vale ressaltar, no entanto, que essas singularidades estão entrelaçadas com a dinâmica da economia e da sociedade como um todo. Assim, não se podem instituir fronteiras nítidas entre os universos culturais dos sujeitos do campo e da cidade, já que ambos compartilham projetos que se assemelham (Carneiro, 2005). 
Considerando a centralidade dos espaços educativos e do grupo de amigos para a socialização de muitos jovens rurais brasileiros, este artigo se propõe a compreender as percepções dos/as jovens de um Distrito localizado em área rural do município baiano de Palmas de Monte Alto, sobre o lugar em que vivem, bem como as experiências cotidianas vivenciadas por estes nos espaços de circulação social. Será apresentada a seguir uma discussão acerca das especificidades concernentes à juventude rural e ao cotidiano, o percurso da pesquisa de campo desenvolvida no distrito e alguns segmentos dos grupos de discussão "As meninas que sonham" e "Os/as jovens que vêm de longe".

Por fim, apresenta-se a análise comparativa destes grupos com o intuito de reconstruir as orientações coletivas, bem como as interações produzidas pelos/as jovens sobre o lugar em que vivem, numa tentativa de compreender as divergências, aproximações e singularidades que marcam as percepções dos grupos.

\section{Juventude rural e cotidiano}

As pesquisas sobre juventude no Brasil, de uma forma geral, transitaram por abordagens que se mostraram limitadas frente à complexidade social dessa categoria. Assim, as indagações elencadas nesses estudos, sobretudo no que se refere à cidadania, são aquelas que constituem os jovens como problemas, especialmente os jovens pobres. Para Abramo (1997, p. 35), “... a acentuação da atenção nas dimensões de vitimização e heteronomia frente às lógicas do sistema acaba por manter invisível e impensável qualquer tipo de positividade das figuras juvenis". $\mathrm{O}$ rompimento com uma concepção discriminatória acerca dos jovens sobretudo do meio popular - pressupõe o entendimento dos contextos particulares de vida de grupos distintos. Dessa forma, falar das questões juvenis implica saber como os (as) jovens constroem determinado modo de vida, sobretudo no que se refere ao conhecimento das formas de agregação e lazer, aos projetos de vida e ao cotidiano, além de dialogar com sua visão de mundo, seus anseios, seus desejos e ideais. O reconhecimento por parte das instituições escolares acerca da diversidade existente nessas dimensões é imprescindível para se pensar ações direcionadas para o público jovem.

O entendimento sobre a juventude rural supõe o reconhecimento da existência de espaços distintos - a exemplo da casa, da vizinhança e da cidade - onde os (as) jovens vivenciam cotidianamente experiências individuais e coletivas. Sobre a importância da comunidade local para os 
jovens rurais, Brandão (1995, p. 136) afirma que "quando há vizinhos por perto, parentes ou não, os grupos de idade alargam os limites da ordem familiar cotidiana e se constituem como os primeiros espaços extrafamiliares de convivência e socialização." Nesses espaços, os jovens constroem relações com amigos, vivenciam o lazer, estabelecem relações com os meios de comunicação de massa, participam de manifestações culturais e religiosas, expressando um sentimento de pertencimento, tanto à comunidade quanto a grupos de jovens. Nesse sentido, as experiências cotidianas dos jovens dependem da intensidade e da riqueza da vida social existente no meio rural (Wanderley, 2006).

O cotidiano visto sob o signo da regularidade, normatividade e repetitividade manifesta-se como um campo de ritualidades, sendo a rotina "um elemento básico das atividades sociais do dia a dia". (Pais, 2003b, p. 28). A vida cotidiana é uma esfera da realidade constituída por fatos anônimos e transitórios, suscetível a mudanças e modificações. Ainda, para Pais, "torna-se necessário que os jovens sejam estudados a partir de seus contextos vivenciais, quotidianos, porque é quotidianamente ... isto é, no curso das suas interações, que os jovens constroem formas sociais de consciência, de pensamento, de percepção e ação". (Pais, 2003a, p. 70). Daí a relevância da valorização do lugar social da juventude rural, com suas especificidades. Para Vieira (2006), contrariamente à ideia ainda vigente de que só restam no campo os mais velhos em algumas regiões do país o meio rural concentra uma parcela significativa de jovens homens e mulheres que constroem distintas trajetórias e formas de pensar e de vivenciar suas condições juvenis.

É importante ressaltar também que, para muitos jovens rurais provenientes dos pequenos municípios brasileiros, a ausência de espaços de lazer e, muitas vezes, a inexistência de um projeto de educação continuada para a juventude rural contribuem para a avaliação negativa do campo em relação à cidade e para o desejo de migração (Wanderlei, 2006). Pensar a juventude rural implica reconhecer seu potencial para a proposição de políticas públicas - que promovam tanto a concessão de terra e crédito para a inserção produtiva como o desenvolvimento da educação do campo e das práticas de sociabilidade e interação social - em uma dimensão que ressignifique o entendimento acerca da juventude e reconheça os jovens em suas diferenças como atores e sujeitos de direitos (Castro, 2007). 


\section{O percurso da pesquisa no Distrito Espraiado}

O município de Palmas de Monte Alto localiza-se na Região Sul sudoeste da Bahia, limitando-se ao norte com Riacho de Santana e Matina, ao sul com Sebastião Laranjeiras, ao leste com Guanambi e ao oeste com Iuiu e Malhada. Dista de Salvador em $840 \mathrm{~km}$. Sua população está estimada em 20.779 habitantes, sendo formada por pequenos agricultores, juntando-se a estes numa relação de complementaridade, comerciantes, funcionários públicos, professores, auxiliares de serviços gerais, profissionais liberais entre outros. A maioria da população ativa concentra-se no meio rural. Tem como principais produtos agrícolas feijão, algodão, mandioca, sorgo, mamona, milho e arroz. O clima é do tipo quente e seco, apresenta uma temperatura média anual de $22^{\circ} \mathrm{C}$, a precipitação anual é de 700/900 mm e seu período chuvoso vai de novembro a janeiro. O risco de seca é considerado médio, o que favorece a agricultura de subsistência, inclusive pela sua extensão em área de 2.787,6 km² (IBGE, 2010). O município é formado pelos Distritos rurais de Espraiado, distante $48 \mathrm{~km}$ da sede; Barra do Riacho, distante 25 km; Pinga Fogo, distante $15 \mathrm{~km} \mathrm{e}$ Rancho das Mães, distante 13 km.
O critério de escolha do Distrito Espraiado para a realização do estudo está aportado no fato de que a oferta de Educação Básica constitui-se em fenômeno recente neste Distrito, haja vista que as áreas rurais de pequenos municípios brasileiros tiveram um processo de escolarização tardio e sexista. Aspectos como a distância da sede do município, a densidade demográfica e as marcas de isolamento também motivaram a realização do estudo. Espraiado foi reconhecido como Distrito em 08 de junho de 2004. Está localizado à margem esquerda do Rio das Rãs e faz divisa com o município de Riacho de Santana-BA.

O colégio no qual foram localizados os(as) os/as jovens é uma instituição de ensino fundamental da rede pública do referido município que funciona nos turnos matutino, vespertino e noturno. O turno matutino é frequentado por crianças oriundas da sede do Distrito, que cursam a educação infantil e os anos iniciais do ensino fundamental. Os/as jovens provenientes das fazendas e sede do Distrito estudam os anos finais no turno vespertino e chegam à escola no ônibus escolar, que transporta estudantes e pessoas da comunidade. No noturno funciona uma turma de Educação de Jovens e Adultos (EJA) frequentada por adultos e jovens, além de turmas de ensino 
médio. Muitos jovens que estudam à tarde e à noite no colégio provêm do Distrito Vesperina, da sede do Distrito e de fazendas vizinhas. São 150 alunos/as que se deslocam das fazendas no transporte escolar rural.

$\mathrm{Na}$ tentativa de reconhecer as especificidades que caracterizam os contextos locais do meio rural, optou-se por realizar uma pesquisa etnográfica na qual a observação participante, as entrevistas com moradores e os grupos de discussão se constituíram como principais instrumentos de coleta de dados. Os grupos de discussão foram formados com jovens estudantes do sexo masculino e feminino, a partir do critério da amizade, ou seja, os próprios jovens determinavam quem participaria do grupo, com a presença de três a seis integrantes por grupo. Foram realizados um total de dez grupos de discussão com jovens oriundos do Distrito e fazendas vizinhas, alunos matriculados nos anos finais do ensino fundamental, faixa etária de 12 a 18 anos, entre os meses de fevereiro e março de 2008. No primeiro momento, optou-se por realizar os grupos com jovens matriculados nos últimos dois anos do ensino fundamental, haja vista que se trata de uma fase em que novas perspectivas e projetos de futuro começam a ser delineados. Questões sobre a continuidade dos estudos, a busca por trabalho na cidade, o ingresso em cursos técnicos fazem parte dos interesses desses jovens.

O processo de formação desses grupos ocorreu de forma tranquila $\mathrm{e}$ acessível. Como os jovens se organizavam em rodas de amigos pelo entorno da escola, a abordagem era feita, considerando a aproximação existente entre eles/as. Observou-se, ainda, que se organizavam em grupos de rapazes e moças, sendo rara a existência de grupo misto. Os grupos de discussão foram realizados seguindo um tópico-guia que trazia os temas de interesse da pesquisa. A interação entre os membros variava de um grupo para outro. Apesar de serem colegas de sala, em alguns grupos a conversa fluía; em outros, alguns membros simplesmente mantinham-se em silêncio durante toda a entrevista. Mas, em quase todos os grupos, assuntos como o fim de semana, família, casamento e eventos escolares eram discutidos com mais entusiasmo. No entanto, na maioria desses grupos, a discussão se limitou aos temas apresentados pela pesquisadora, ainda que ao final da discussão fossem novamente instigados a falar sobre assuntos que não haviam sido discutidos. Ao término dos grupos de discussão, com o objetivo de obter informações adicionais, cada participante preenchia um questionário 
com informações relevantes para a constituição do perfil de cada um.

Em seguida, deu-se início à análise dos dados empíricos. Primeiramente, realizou-se a transcrição e divisão temática dos grupos de discussão realizados com os/as jovens. Essa divisão compreende a identificação das passagens/subpassagens e da metáfora de foco. Embora todos trouxessem aspectos importantes para serem analisados, a escolha de grupos representativos para a análise era necessária.

Nesse sentido, foi feita a transcrição completa e codificada $^{1}$ de três grupos, tendo o cuidado de preservar as marcas de oralidade dos entrevistados, na tentativa de garantir o reconhecimento do dialeto local e da densidade interativa presente nos grupos. Para a análise, foram escolhidos os grupos "Os/as jovens que vêm de longe" e "As meninas que sonham." A escolha está aportada nas especificidades apresentadas pelos referidos grupos, tais como o local de moradia e as representações de gênero. Os/as jovens dos referidos grupos residem nas localidades mais distantes e buscam o desenvolvimento educacional, a partir da projeção de uma possível saída em direção às cidades. São representantivos para o debate acerca das intersecções existentes entre as dimensões educação escolar, de gênero e migração, presentes no estudo desenvolvido. $\mathrm{O}$ processo de análise destes foi feito a partir do método documentário de interpretação desenvolvido por Karl Mannheim e adaptado para a pesquisa social empírica por Ralf Bohnsack (cf. Weller, 2010 e Bohnsack e Weller, 2006). Considerando os limites do presente artigo será apresentado a seguir o segmento que aborda os significados de morar no meio rural, para os/as participantes dos grupos de discussão "Os/as jovens que vêm de longe" e "As meninas que sonham". Os termos 'longe' e 'sonham' destacam aspectos que caracterizam os/as jovens que compõem o grupo. O primeiro grupo reside no lugar mais 'longe' da escola. São aqueles que convivem diariamente com as longas distâncias. O segundo grupo traz o 'sonho' como uma projeção muito presente na fala das jovens. Os projetos são também sonhos, conforme demonstram quando falam sobre o futuro. No primeiro momento, faz-se uma breve apresentação do perfil dos membros de cada grupo. Em seguida, a análise do segmento, destacando as visões de mundo e as experiências compartilhadas pelos grupos.

\section{Os/as jovens que vêm de longe Moisés}

Moisés (Mm) tem 17 anos, religião católica, negro, natural da fazenda Cedro, em Palmas de Monte Alto-BA. Mora nessa 
fazenda desde que nasceu na companhia dos pais. Tem 7 irmãos e irmãs. Sua mãe nasceu na fazenda Malhada Grande, é lavradora e ganha $\mathrm{R} \$ 15,00$ por dia. Seu pai nasceu na fazenda Papaconha, é lavrador e ganha $\mathrm{R} \$ 15,00$ por dia. Ambos cursam a Educação de Jovens e Adultos à noite, na fazenda Cedro. Moisés estudou os anos iniciais do ensino fundamental na Escola Municipal Santo Onofre, localizada na fazenda Cedro. No momento atual, cursa o nono ano e seu lazer preferido é praticar esporte. Frequenta um grupo há seis meses na igreja, de quinze em quinze dias, para brincar e realizar atividades orais.

\section{Tatiana}

Tatiana (Tf) tem 13 anos, religião católica, negra, natural da fazenda Cedro, em Palmas de Monte Alto-BA. Mora com os pais nessa fazenda desde que nasceu. Tem 7 irmãos e irmãs. Sua mãe é zeladora e foi a primeira professora da localidade. Tatiana não informou a naturalidade dos pais, a renda, a escolaridade e a ocupação do pai. Estudou os anos iniciais do ensino fundamental na Escola Municipal Santo Onofre, localizada na fazenda Cedro. Atualmente, cursa o sexto ano e tem como lazer preferido estudar. Frequenta um grupo, a cada quinze dias, há 6 meses na igreja.

\section{Carla}

Carla (Cf) tem 16 anos, religião católica, negra, natural da fazenda Cedro, em Palmas de Monte Alto-BA. Sempre residiu nessa fazenda com os pais. Tem 9 irmãos e irmãs. Sua mãe nasceu em Malhada, trabalha em casa e cursa a Educação de Jovens e Adultos à noite na fazenda Cedro. Seu pai é lavrador e ganha $\mathrm{R} \$ 15,00$ por dia. Carla não informou a escolaridade dos pais e a naturalidade do pai. Estudou os anos iniciais do ensino fundamental na Escola Municipal Santo Onofre, localizada na fazenda Cedro. Atualmente, cursa o sétimo ano e tem como lazer preferido brincar de futebol com as amigas. Participa de um grupo há três meses. Encontram-se a cada quinze dias, na igreja, para fazer leituras bíblicas e brincar.

\section{Wesley}

Wesley (Wm) tem 14 anos, religião católica, negro, natural da fazenda Cedro, em Palmas de Monte Alto-BA. Reside na fazenda desde que nasceu. Tem 4 irmãos e irmãs. Sua mãe é lavradora e ganha $\mathrm{R} \$ 15,00$ por dia. Seu pai é lavrador e ganha $\mathrm{R} \$ 15,00$ por dia. Ambos estão cursando a Educação de Jovens e Adultos à noite na fazenda Cedro. Wesley não informou a escolaridade e a naturalidade dos pais. Estudou os anos iniciais do ensino fundamental na Escola Municipal Santo Onofre, localizada na fazenda Cedro. 
Atualmente, cursa o oitavo ano e tem como lazer preferido jogar futebol. Participa de um grupo, há seis meses, a cada quinze dias, na igreja de Santo Expedito. Nesse grupo, realiza atividades orais $\mathrm{e}$ brincadeiras.

\section{Carlos}

Carlos $(\mathrm{Cm})$ tem 16 anos, religião católica, negro, natural da fazenda Cedro, em Palmas de Monte Alto-BA. Mora nessa fazenda desde que nasceu, com os pais. Tem 7 irmãos e irmãs. Sua mãe nasceu no Estado de São Paulo, é zeladora e tem o ensino fundamental completo. Seu pai é lavrador. Não informou a renda dos pais, bem como a escolaridade e naturalidade do pai (escreveu que não sabe a naturalidade do pai). Estudou os anos iniciais do ensino fundamental na Escola Municipal Santo Onofre, localizada na fazenda Cedro. Cursa o sétimo ano e trabalha na "panha" de feijão. Informa que trabalha $3 \mathrm{~h}$ e que o valor que ganha gasta com alimentação. Seu lazer preferido é o jogo de futebol. Participa de um grupo há 1 ano, 2 vezes para rezar, brincar e cantar rezas.

\section{João}

João (Jm) tem 18 anos, religião católica, negro, natural de Palmas de Monte Alto-BA.Tem domicílio na fazenda Curral Novo desde que nasceu. Tem 6 irmãos e irmãs (morreram 2 irmãos/ãs). Sua mãe nasceu em Candiba-BA, é lavradora e ganha $\mathrm{R} \$ 15,00$ por dia. Seu pai é lavrador e ganha $\mathrm{R} \$ 15,00$ por dia. Informa não saber a escolaridade dos pais e a naturalidade do pai. Estudou os anos iniciais do ensino fundamental na Escola Municipal José Pinto Lima, localizada na fazenda Curral Novo. Cursa o oitavo ano e trabalha. Seu lazer preferido é jogar futebol. Participa de um grupo há 1 ano, a cada quinze dias. Nesse grupo, reza, brinca e realiza atividades orais.

\section{A comunidade vive em paz e em solidariedade}

As diversas fazendas que fazem parte do Distrito Espraiado se constituem como "moradas" de muitos jovens estudantes que deslocam-se diariamente em direção à escola. $\mathrm{Na}$ tentativa de conhecer o cotidiano dessas localidades, bem como os significados que atribuem ao "rural" em que vivem, a pesquisadora propõe aos jovens que falem sobre a vida na fazenda Cedro (Passagem Meio rural, linhas 103125):

Y: Todo mundo aqui mora em Cedro?

Wm: Esse daqui não esse daqui mora na fazenda Curral Novo

Y: como é que é pra vocês morar no Cedro e no Curral Novo?

Wm: É

Y: LComo que é a vida lá?

Wm: A vida lá é assim muitos lá a comunidade lá é sempre gosta de ajudar uns aos outros ajuda também a 
os povo lá é tudo bom ; lá e também lá é bom pra viver e e ; tem mais outras coisas

Mm: A vida na fazenda Cedro é muito é muito boa ninguém tem inimigo vive tod- todo mundo quando faz um faz quando tem casamento quando morre alguma pessoa a união lá é sempre boa não tem desigualdade não tem agressão graças a Deus lá nós vivemo tudo na paz e todos somos solidários um com o outro

Cm: Pra mim assim um lugar que tá muito distante um do outro igual Curral Novo e Cedro não acho diferença nenhuma né porque sempre a pessoa acha amigo e também sempre ta junto não tem não tem inimigo não briga nem nada dia de sábado assim também a gente encontra com os amigo e faz favor pro outros (2) ${ }^{\circ}$ não acho nada de diferente $^{\circ}$

(3)

Cf: Pra mim também eu não acho não é mo- nada assim não tem diferença nenhuma morar na fazenda Cedro e Curral Novo porque mesmo assim as pessoas morando distante se precisar de alguém aí está sempre pronto pra ajudar

Tf: Pra mim também não não tem diferença assim de Curral Novo com a fazenda Cedro porque uma pessoa precisar de ajuda é só lá e pedir para alguma pegar e ajudar

Jm: Pra mim também não (1) não tem de Cedro pra Curral Novo é que ali dialogamos com os amigos não tem

(2) respeita uns aos outros não tem diferença nenhuma.

Os/as jovens atribuem um valor positivo ao espaço físico e afetivo em que vivem, como bem expressa Wesley ao dizer que "lá é tudo bom; ... e também lá é bom pra viver". Destacam que a solidariedade existente no grupo preserva a amizade entre eles, ainda que morem em fazendas distintas.

Nesse sentido, a vida social na fazenda Cedro parece não ser afetada pelas dificuldades existentes em decorrência das longas distâncias que a separam da sede do Distrito e da sede do município. Morar na fazenda Cedro é viver numa comunidade unida, solidária e pacífica. É assim que os/as jovens apresentam a sua "morada" que se constitui não apenas como espaço físico destinado às suas necessidades -, mas como lugar de vida. É o modo como se vive cotidianamente: “Graças a Deus lá nós vivemo tudo na paz e todos somos solidários um com o outro", que ressignifica o "lugar de morada".

A proposição inicial de Wesley e, em seguida, a exemplificação feita por Moisés - "quando tem casamento, quando morre alguma pessoa, a união lá é sempre boa" permitem afirmar que as relações estabelecidas na localidade são regidas pela solidariedade existente no grupo, aqui representada pela ajuda prestada e pela partilha dos momentos de alegria e de dor. Esses princípios parecem estruturar a vida local e são eles que certamente motivam os jovens a permanecer na localidade. 
Estar pronto para ajudar - ainda que o beneficiado pela ajuda more em outra localidade - é uma demonstração de que os infortúnios $^{2}$ dos outros podem ser partilhados na comunidade a qualquer tempo, o que garante a unidade do grupo. O fortalecimento dos vínculos da vida local é garantido quando todos se disponibilizam a ajudar aqueles que precisam de apoio. Em muitas localidades rurais, os moradores enfrentaram catástrofes naturais como longas estiagens e enchentes. Portanto, faz parte das normas que regem o "lugar" socorrer aos que precisam, ainda que não façam parte do núcleo familiar.

A convivência entre membros de gerações distintas fortalece os valores que são relevantes para o grupo, historicamente. As recordações dos "velhos do lugar" sobre o "tempo antigo" na fazenda, bem como os princípios da boa convivência provavelmente influenciam o processo de socialização desses jovens.

A vivência coletiva dos rituais de passagem também é referenciada positivamente pelos/as jovens, pois se constitui em uma prática que assegura o valor de estarem juntos. O mutirão para a preparação dos casamentos ${ }^{3}$ é um costume muito comum nas localidades rurais, sendo que a união em torno da organização desse momento envolve todos os moradores, o que aponta a dimensão coletiva como aspecto que move os eventos realizados na comunidade. Também quando a vida é interrompida, todos se fazem presentes em solidariedade à dor dos que ficam. A presença que conforta, bem como as ajudas necessárias aos que "padecem" pela perda do ente querido, figuram como experiências que estão inscritas no cotidiano local. Estar juntos em comunhão nesses momentos reforça o sentimento de pertença ao meio que estão inseridos.

Assim, o rural não é construído apenas a partir da utilização do espaço, mas através da vida que é gestada cotidianamente no coletivo. É na família e no grupo de vizinhança que os/as jovens vivenciam as rotinas da vida rural, trocando e partilhando experiências, conflitos e projetos. Estar imerso nestes espaços possibilita apreender a memória coletiva que sustenta as relações tecidas no grupo e que são ressignificados pelos/as jovens.

\section{As meninas que sonham Daniela}

Daniela (Df) tem 14 anos, religião católica, branca, natural da fazenda Angico, em Palmas de Monte Alto-BA. Mora no Distrito Espraiado, há 12 anos com os pais. Tem 5 irmãos e irmãs. Sua mãe nasceu na fazenda Angico, tem o ensino fundamental incompleto, é gari e 
ganha $\mathrm{R} \$ 70,00$ por mês. Seu pai nasceu em Angico, tem ensino fundamental incompleto, trabalha em associação. Não informou a renda do pai. Daniela estudou os anos iniciais do ensino fundamental na Escola Municipal Wilson Lins, em Espraiado. Cursa o nono ano e trabalha ajudando em casa, durante a semana. Seu lazer preferido é jogar baleado. Não participa de grupo ou associação.

\section{Bruna}

Bruna (Bf) tem 14 anos, religião católica, negra, natural de Guanambi-BA. Mora na fazenda Muquém com os pais, desde que nasceu. Tem 4 irmãos e irmãs. Sua mãe nasceu na fazenda Muquém, trabalha em casa e tem o ensino fundamental completo. Seu pai nasceu na fazenda Muquém, é agricultor e tem ensino fundamental completo. Não informou a renda dos pais. Bruna estudou os anos iniciais do ensino fundamental na Escola Municipal Wilson Lins, no Distrito Espraiado. No momento atual cursa o nono ano. Seu lazer preferido é o futebol. Não participa de grupo ou associação.

\section{Geane}

Geane (Gf) tem 12 anos, religião católica, branca, natural de Palmas de Monte Alto-BA. Mora com os pais no Distrito Vesperina, desde que nasceu. Tem 1 irmã. Sua mãe é professora, tem ensino superior completo e Pós-graduação lato sensu. Seu pai é funcionário da limpeza geral $\mathrm{e}$ tem $\mathrm{o}$ ensino fundamental completo. Não soube informar a naturalidade dos pais. Também não informou a renda de ambos. Estudou os anos iniciais do ensino fundamental no Colégio Municipal Marciano Antonio Batista, localizado em Vesperina. No momento atual, cursa o nono ano. Seu lazer preferido é brincar. Não participa de grupo ou associação.

Ser jovem e morar no meio rural: "O modo de vida" em Vesperina, Muquém e Espraiado

Conhecer as singularidades do cotidiano dessas jovens é fundamental para compreendermos a percepção e a ação destas sobre o meio em que estão inseridas (Pais, 2003a). A proposição sobre a vida na localidade em que residem as jovens veio junto com a identificação da moradia de cada uma. Embora estudem na mesma escola, proveem de espaços distintos (Passagem Meio rural, linhas 207-232):

Y: Gente e como que é viver aqui em Espraiado na localidade que vocês moram, você disse que é de Bf: Muquém Y: Muquém Gf: Vesperina Df: Espraiado. Y: Então como é que é morar nesses lugares?

Gf: Lá na (1) Vesperina que tem o apelido também de Urtiga (1) assim é sossegado (2) as vezes é ruim não tem nem nem uma festa pra gente ir não tem uma loja pra gente entrar e 
comprar roupa lá só tem uma não tem uma pizzaria para quando a gente quiser ir lá comer tem não tem (1) assim mas o modo de vida lá é bom Bf: no Muquém também porque lá é um lugar em paz todos são parentes e um respeita os outros as vezes nós gente faz festas outras vez gente faz (1) é (2) quando não tem o que comemorar a gente junta todas todas as família e faz uma comemoração como a semana santa é a festa do São João faz uma festa na casa de de uma qualquer pessoa

Df: aqui aqui no Espraiado é bom como como elas já apesar delas já ter falado aqui (2) aqui também é um lugar sossegado a não ser assim dia de quando tem uma festa tem muita brigas muitas brigas assim muito barulho às vezes também não tem lá perto de casa mesmo tem tem um um vizinho lá que ele de vez em quando que ele que ele bebe aí ele começa a zoar à noite não deixa ninguém dormir fica perturbando mas é bom também a mesma coisa aqui em Espraiado é bom que agora agora tá tendo essa essa pracinha aí os menino os menino diverte muito o colégio à noite que antes antes (( barulho de moto)) de ter o colégio antes de não dos alunos não estudarem à noite era ruim essa rua era sem graça agora os meninos vem pra aí muita gente sai=sai da pracinha vem pra aí sai de casa pra não ficar em casa assim sozinha assim (1) sem graça sem graça vem para aí e aí vão animando aqui o Espraiado é bom.

Inicialmente, a entrevistadora coloca uma pergunta sobre a vida em Espraiado, mas, estando em dúvida sobre o local de moradia, dirige-se às jovens que atendem ao pedido, informando os nomes das respectivas localidades em que residem. Y retoma a pergunta trocando o verbo intransitivo "viver" pelo verbo "morar". Ambos têm acepções diferentes, sendo a primeira talvez mais completa, pois traz à tona aspectos concernentes à labuta, ao dia a dia, à organização sociocultural na comunidade.

Geane inicia apresentando o nome da localidade em que mora - Vesperina - ao mesmo tempo em que informa o apelido do local (Urtiga). Essa explicação pode estar associada à necessidade de referenciar seu local de "morada" com mais familiaridade, já que esse distrito rural é um dos mais antigos e conhecidos na região. Em seguida, aponta o local como sossegado, ao mesmo tempo em que "às vezes é ruim", em virtude de existirem limitações como: ausência de festas, diversidade de lojas para comprar roupa e inexistência de uma pizzaria para frequentar. No entanto, considera o "modo de vida lá" bom.

A privação de não ter espaços e serviços destinados ao entretenimento no meio rural constitui-se em insatisfação para muitos jovens, que gostariam de usufruir de formas de lazer e de consumo semelhantes àquelas vividas pelos jovens nos meios urbanos. Geane propõe o acesso a espaços que promovem outras práticas de sociabilidade e instituem novas necessidades de consumo. A expressão “às 
vezes é ruim", proposta inicialmente por Geane para referenciar as ausências da localidade, parece não ser suficiente para anular o significado positivo atribuído à vida social, tal como expressa sua fala “mas o modo de vida lá é bom”.

Em concordância com Geane, Bruna apresenta positivamente a localidade em que mora - o Muquém -, apontando as dimensões de paz, respeito e parentesco como elementos que organizam a vida cotidiana. Nessa localidade a organização social se sustenta nas redes de parentesco constituídas ao longo do tempo, sendo que a influência dos "mais velhos do lugar" traduz-se em característica marcante.

A paz e o respeito que perpassam a vida comunitária são princípios que fortalecem os vínculos familiares, que se constituem para além das necessidades em torno da sobrevivência. É a busca pela celebração coletiva "a gente junta todas as famílias e faz uma comemoração", através da realização de festas nas casas que move as relações na comunidade. Acontecimentos como o São João e a Semana Santa marcam o cotidiano e estão ligados às relações estabelecidas nas famílias, que abrem as portas de suas casas para festejar.

Complementando a fala das colegas, Daniela apresenta o Distrito Espraiado como lugar pacífico, embora demonstre indignação com algumas "desordens" ocorridas no dia-a-dia. $\mathrm{O}$ que motiva Daniela a referenciar o local positivamente é a existência de espaços públicos de lazer. Ao apresentarem a localidade onde moram como lugar de sossego, respeito e paz, as jovens atribui um valor positivo à sua morada. O reconhecimento da relevância dessas dimensões pode estar atrelado ao fato de que, em muitas áreas rurais, os jovens encontram-se vulneráveis a situações de violência, consumo de drogas, entre outras. As observações das jovens sobre o lugar onde vivem também são marcadas pela existência ou não de espaços destinados às práticas de sociabilidade no meio rural. A existência de uma pizzaria, a casa de parentes e a pracinha constituem-se em lugares de encontro e diversão relevantes para essas jovens, além de impactar na avaliação que fazem sobre o "modo de vida" no meio rural.

A pracinha e o colégio são apontados como lugares destinados para a interação social tanto entre os jovens como entre outros sujeitos da comunidade. Outro aspecto destacado positivamente é o fato de Espraiado possuir vida noturna com a abertura do ensino médio nesse período. Esse aspecto parece central, pois até então a vida noturna era um elemento diferenciador entre o campo e a cidade. 
Desde a abertura do ensino médio as pessoas passaram a frequentar a pracinha e outras possibilidades de sociabilidade e de lazer foram surgindo: "essa rua era sem graça." A dimensão socializadora desses locais figura como elemento necessário para romper com as condições de vida marcadas pelo confinamento no espaço da casa, por exemplo. As possibilidades de interação e partilha existentes nesses lugares - "agora tá tendo essa pracinha aí, os menino diverte muito o colégio à noite..." - constituem-se como aspectos importantes para a jovem.

\section{Análise comparativa dos grupos de discussão: algumas considerações}

A presente análise busca reconstruir as orientações coletivas dos grupos "Os/as jovens que vêm de longe" e "As meninas que sonham," bem como as interações produzidas pelos/as jovens sobre o lugar em que vivem, numa tentativa de compreender as divergências, aproximações e singularidades que marcam as percepções dos grupos.

As orientações coletivas do grupo "Os/as jovens que vêm de longe" sobre a vida na fazenda Cedro apontam o rural como lugar "prenhe" de vida, que é regido pela solidariedade, amizade e paz. Para os rapazes e as moças, é relevante viver num lugar onde o respeito perpassa as relações tecidas tanto nos espaços de lazer como nos espaços de trabalho, o que torna a existência significativa. Assim, ao contrário de muitos jovens rurais que transitam no meio urbano para estudar, trabalhar e se divertir, "os/as jovens que vêm de longe" vivem a sua condição de moça e rapaz apenas no meio rural e de forma intensa, haja vista a existência de diversos espaços destinados às práticas de sociabilidade. Esse modo de ser jovem possibilita rever concepções que apontam o rural como lugar sem lazer, destituído de lugares para diversão.

Embora "As meninas que sonham" positivem a vida na localidade em que moram, em razão da existência do respeito e da paz como princípios que regem a vida na comunidade, o grupo traz outros aspectos sobre a vida na localidade que chamam sua atenção. Por exemplo: a ausência de espaços destinados à vivência de experiências relacionadas às práticas de consumo e de lazer, destacado por Geane, incomoda as jovens que concebem essas ausências como privações, o que faz com que talvez a cidade seja vista como lugar atraente.

As orientações coletivas desses dois grupos no tocante às relações estabelecidas na comunidade são bem distintas. Os/as jovens que vivem na fazenda Cedro parecem vivenciar o cotidiano de forma menos conflitante, sobretudo nas trocas 
experimentadas nos espaços de lazer. Os membros dos dois grupos moram em áreas distintas, Fazenda Cedro e sede do Distrito Espraiado, sendo que esses espaços apresentam singularidades, especialmente no que se refere à organização sociocultural da localidade.

\section{Considerações finais}

A existência de diversos "modos de vida" no meio rural brasileiro figura como elemento importante para pensar as políticas públicas educativas destinadas para os jovens do meio rural, dado o significado positivo atribuído pelos jovens aos seus territórios de vida, de pertença. Estas políticas devem partir dos diferentes sujeitos do campo, além de estarem aportadas em seus contextos vivenciais, numa perspectiva que reconheça as vozes que foram silenciadas em épocas passadas. Para isso faz-se necessário compreender como os/as jovens rurais vivenciam a sua condição juvenil, relacionam-se com o mundo do trabalho, projetam o futuro e quais os significados atribuídos às suas experiências escolares.

A ampliação da escolaridade de moças e rapazes residentes em áreas rurais de pequenos municípios brasileiros deve perpassar as discussões sobre a educação do campo, gestadas em vários espaços formativos. Surge o desafio de ofertar uma educação que, além de contemplar os saberes, a memória coletiva e a positivação dos processos identitários no meio rural, possibilite também aos/às jovens o diálogo em outros contextos educativos.

Também é preciso considerar o impacto e significado atribuídos a programas educativos como o PETI (Programa de Erradicação do Trabalho Infantil), a instituições como o Conselho Tutelar da Infância e do Adolescente, aos programas Bolsa Escola e Bolsa Família, pelos/as jovens rurais, sobretudo no que se refere à relação estabelecida com a escola. A existência desses programas parece transcender as necessidades de sobrevivência da população, uma vez que a referência feita a estes aponta outros elementos que modificam o cotidiano desses sujeitos, especialmente no que concerne à relação com o trabalho rural.

A formulação de políticas públicas educativas deve estar articulada, ainda, com um projeto de país e de campo que reconheça a existência do meio rural como lugar de vida, trabalho, cultura e lazer. Isso implica considerar outras especificidades dos contextos sociais dos/as jovens, a exemplo das relações de gênero estabelecidas, do pertencimento étnico, das práticas religiosas e das relações intergeracionais. No momento presente, não é mais possível pensar a vida dos 
homens e mulheres rurais sem que essas questões sejam reconhecidas. Afinal, os/as jovens rurais brasileiros estão clamando pelo respeito por seus "modos de vida", seus tempos de aprendizagem e suas condições como sujeitos de direitos - tal como fica explícito nos espaços formativos frequentados por esta parcela da população.

\section{Referências}

Abramo, H. (1997). Considerações sobre a tematização social da juventude no Brasil. Revista Brasileira de Educação, 5(6), 2536.

Abramovay, R. (2004). Dilemas e estratégias dos jovens rurais: ficar ou partir. Estudos Sociedade e Agricultura, 12, 236-271.

Bohnsack, R., \& Weller, W. (2006). O método documentário e sua utilização em grupos de discussão. Educação em Foco, 11, 19-38.

Brandão, C. R. (1995). A partilha da vida. São Paulo: GEIC/Cabral.

Carneiro, M. (2005). Juventude rural: projetos e valores. In Abramo, H.; \& Branco, P. (Orgs.), Retrato da juventude brasileira: análise de uma pesquisa nacional. (p. 243-261). São Paulo, SP: Editora Fundação Perseu Abramo.

Castro, E., \& Carneiro, M. (2007). Juventude rural em perspectiva. Rio de Janeiro: Mauad X.

Dayrell, J. (2007). A escola 'faz' as juventudes? Educação e Sociedade, 28(100), 105-128.
Instituto Brasileiro de Geografia e Estatística - IBGE. Municípios brasileiros. Disponível em: <http://ibge.gov.br>. Acesso em: 4 abr. 2010.

Margulis, M. (2001). Juventud: una aproximación conceptual. In Burak, S. (Org). Adolescencia y juventud en América Latina. (p. 41-73). Costa Rica: LUR.

Pais, J. (2003b). Vida cotidiana: enigmas e revelações. São Paulo: Cortez.

Pais, J. (2003a). Culturas juvenis. Lisboa: Imprensa Nacional/Casa da Moeda.

Pereira, J. (2004). Entre campo e cidade: amizade e ruralidade segundo jovens de Nova Friburgo. Estudos Sociedade $e$ Agricultura, 12, 322-351.

Stropasolas, V. (2006). O mundo rural no horizonte dos jovens. Florianópolis: Editora da UFSC.

Veiga, J. (2003). Cidades imaginárias: o Brasil é menos urbano do que se calcula. Campinas, SP: Autores Associados.

Vieira, R. (2006). Tem jovem no campo! Tem jovem homem, tem jovem mulher. In Woortmann, E., \& Menache, R.; Heredia, B.(Orgs.). Margarida Alves: coletânea sobre estudos rurais e gênero. (p. 195-214). Brasília: MDA, IICA.

Wanderley, M. (Coord.). (2006). Juventude rural: vida no campo e projetos para o futuro. Relatório de Pesquisa. Recife.

Weisheimer, N. (2005). Juventudes rurais: mapa de estudos recentes. Brasília: MDA/NEAD.

Weller, W. (2011). Minha voz é tudo o que eu tenho: manifestações juvenis em Berlin e São Paulo. Belo Horizonte: Editora UFMG. 
Weller, W. (2010). Grupos de discussão: aportes teóricos e metodológicos. In Weller, W., \& Pfaff, N. (Orgs.). Metodologias da pesquisa qualitativa em educação: teoria e prática. (p. 54-66). Rio de Janeiro: Vozes.

Weller, W. (2005). A contribuição de Karl Mannheim para a pesquisa qualitativa: aspectos teóricos e metodológicos. Sociologias, 13, 260-300.

Weller, W. (2006). Grupos de discussão na pesquisa com adolescentes e jovens: aportes teórico-metodológicos e análise de uma experiência com o método. Educação e Pesquisa, 32(2), 241-260.

Anexo I: Códigos utilizados na transcrição das entrevistas (modelo criado pelos pesquisadores do grupo coordenado por Ralf Bohnsack, na Alemanha)

Y: abreviação para entrevistador (quando realizada por mais de um entrevistador, utiliza-se Y1 e Y2)

Am/Bm: abreviação para entrevistado/entrevistada. Utiliza-se " $\mathrm{m}$ " para entrevistados do sexo masculino e "f" para pessoas do sexo feminino. Numa discussão de grupo com duas mulheres e dois homens, por exemplo, utiliza-se: Af, Bf, Cm, Dm e dá-se um nome fictício ao grupo. Essa codificação será mantida em todos os levantamentos subseqüentes com as mesmas pessoas. $\mathrm{Na}$ realização de uma entrevista narrativa-biográfica com um integrante do grupo entrevistado anteriormente, costuma-se utilizar um nome fictício que inicie com a letra que a pessoa recebeu na codificação anterior (por exemplo: $\mathrm{Cm}$, Carlos).

?m ou ?f: utiliza-se quando não houve possibilidade de identificar a pessoa que falou (acontece algumas vezes em discussões de grupo quando mais pessoas falam ao mesmo tempo).
(.) um ponto entre parênteses expressa uma pausa inferior a um segundo.

o número entre parênteses expressa o tempo de duração de uma pausa (em segundos).

$\Gamma \quad$ utilizado para marcar falas iniciadas antes da conclusão da fala de outra pessoa ou que seguiram após uma colocação.

do tom da voz.

ponto e vírgula: leve diminuição

ponto: forte diminuição do tom

da voz.

vírgula: leve aumento do tom

da voz.

exem- $\quad$ palavra foi pronunciada pela metade.

exem:::plo pronúncia da palavra foi esticada ( a quantidade de : equivale o tempo da pronúncia de determinada letra).

assim=assim palavras pronunciadas de forma emendada.

exemplo palavras pronunciadas de forma enfática são sublinhadas.

${ }^{\circ}$ exemplo ${ }^{\circ} \quad$ palavras ou frases pronunciadas em voz baixa são colocadas entre pequenos círculos.

exemplo palavras ou frases pronunciadas em voz alta são colocadas em negrito.

(example) palavras que não foram compreendidas totalmente são colocadas entre parênteses.

( ) parênteses vazios expressam a omissão de uma palavra ou frase que não foi compreendida (o tamanho do espaço vazio entre parênteses varia de 
acordo com o tamanho da palavra ou frase).

(:) exemplo (-) palavras ou frases entre risos são colocadas entre emoticon.

() (2) () número entre sinais de emoticon expressa a duração de risos assim como a interrupção da fala.

((bocejo)) expressões não-verbais ou comentários sobre acontecimentos externos, por exemplo: ((pessoa acende cigarro)), ((pessoa entra na sala e a entrevista é brevemente interrompida)) ((risos)).

$/ / \mathrm{hm} / /$

utilizado apenas na transcrição de entrevistas narrativasbiográficas para ou // (;) (1) :)// indicar sinais de feedback ("ah," "oh," "mhm") ou risos do entrevistador.

\section{Notas:}

1.Weller (2005) considera relevante numerar as frases dos membros do grupo, bem como criar códigos para apresentar a entonação da $\mathrm{voz} \mathrm{e}$ as expressões produzidas pelos participantes. Também assinala a importância de apresentar nomes fictícios para os membros, garantindo assim o anonimato destes.

2.Durante a entrevista com uma moradora de outra fazenda fui informada sobre as "dificuldades passadas" por uma família que morava próximo de sua casa. Falava das "ajudas" que essa família recebia da comunidade, ao mesmo tempo em que pedia para que eu os visitasse.

3.Uma jovem integrante desse grupo descreve em seu diário o envolvimento da comunidade na preparação do casamento de uma prima, que vai desde às tarefas de "pilar o milho" até o prazer de acompanhar os noivos em direção à sede do município para a realização da cerimônia.
Recebido em: 08/07/2016

Aprovado em: 26/07/2016

Publicado em: 19/04/2017

Como citar este artigo / How to cite this article / Como citar este artículo:

APA:

Silva, C. M. (2017). Morar no meio rural: o cotidiano $\mathrm{dos} /$ das jovens rurais de um município baiano. Rev. Bras. Educ. Camp., 2(3), 106-126.

ABNT:

SILVA, C. M. Morar no meio rural: o cotidiano dos/das jovens rurais de um município baiano. Rev. Bras. Educ. Camp., Tocantinópolis, v. 2, n. 3, p. 106-126, 2017. 